\title{
SOSYAL MEDYA
}

\section{KULLANIM BOZUKLUĞU}

Uzm. Elif ALUÇ GÜLŞEN - Doç. Dr. Elif YÖYEN 


\section{(C) Copyright 2021}

Bu kitabın, basım, yayın ve satış hakları Akademisyen Kitabevi A.Ş.'ne aittir. Anılan kuruluşun izni alınmadan kitabın tümü ya da bölümleri mekanik, elektronik, fotokopi, manyetik kağıt ve/veya başka yöntemlerle çoğaltılamaz, basılamaz, dağıtılamaz. Tablo, şekil ve grafikler izin alnmmadan, ticari amaçh kullanılamaz. Bu kitap T.C. Kültür Bakanlı̆ı bandrolü ile satılmaktadır.

\section{ISBN}

978-625-7409-00-1

\section{Kitap Adı}

Sosyal Medya Kullanım Bozukluğu

\section{Yazar}

Elif ALUÇ GÜLŞEN

ORCID iD: 0000- 0002- 0678- 8527

Elif Güneri YÖYEN

ORCID iD: 0000-0002-0539-9263

\section{Yayın Koordinatörü \\ Yasin DİLMEN}

Sayfa ve Kapak Tasarımı

Akademisyen Dizgi Ünitesi

\section{Yayıncı Sertifika No}

47518

Baskı ve Cilt

Vadi Matbaacılık

Bisac Code

SOC052000

DOI

$\mathrm{xxx}$

\section{GENEL DAĞITIM}

\section{Akademisyen Kitabevi A.Ş.}

Halk Sokak 5 / A

Yenişehir / Ankara

Tel: 03124311633

siparis@akademisyen.com

\section{www.akademisyen.com}




\section{YAZARLAR HAKKINDA}

\section{Elif Aluç GÜLŞEN}

Elif Aluç Gülşen, 2012 yılında Anadolu Üniversitesi Sosyoloji bölümünü bitirmiştir. 2019 yılında Psikoloji alanında yüksek lisanasını "Sosyal Medya Kullanım Bozukluğu Ölçeğinin Türkiye’de Yetişkinlere Uyarlanması: Geçerlik ve Güvenirlik Çalışması” teziyle İstanbul Gelişim Üniversitesi’nde tamamlamıştır. Gülşen, 2014 yilından bu yana İstanbul Gelişim Üniversitesi idari kadrosunda yönetici olarak çalışmaktadır.

\section{Elif Güneri YÖYEN}

Doçent Doktor Elif Yöyen, 2005 yılında İstanbul Üniversitesi Fen Edebiyat Fakültesi Psikoloji bölümünü ve 2006 yılında aynı üniversitenin Eski Yunan Dili ve Edebiyatı bölümünü bitirdikten sonra, 2008 yılında "Şizofreni ve Bipolar Affektif Bozukluk Hastalarının Rorschach Protokolü Açısından Karşılaştırılması" tezi ile Klinik Psikoloji yüksek lisansını tamamlamıştır. 2012 yılında İstanbul Üniversitesi Adli Tip Enstitüsü Sosyal Bilimler Alanı, Adli ve Klinik Bilimler Alt Alanında "Yatan ve Poliklinikten Takip Edilen 1. Eksen Psikiyatrik Bozukluk Tanısı Almış Kişilerde Şiddet Davranışı ve Eğilimlerinin Karşılaştırılması" konulu tezi ile doktorasını tamamlamıştır. 2005-2014 yılları arasında Erenköy Ruh ve Sinir Hastalıkları Hastanesinde Uzman Klinik Psikolog olarak görev yapan yazar, 2014 yılından beri öğretim üyesi olarak çalışmalarına devam etmektedir. Sakarya Üniversitesi’nde Psikoloji Anabilim Dalı Uygulamalı Psikoloji Bölümünde Doçent Doktor olan yazarın, çok sayıda uluslararası ve ulusal makalesi, kongrelerde sunulmuş bildirileri, kitapları ve kitap bölümleri bulunmaktadır. 


\section{IÇiNDEKILER}

GİRIŞ. 1

\section{BÖLÜM}

ARAŞTIRMAYA GENEL BAKIŞ ...........................................5

1.1. Araştırmanın Amac1 ....................................................................... 5

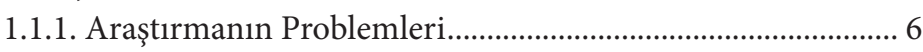

1.1.2. Araştırmanın Alt Problemleri ..................................................... 7

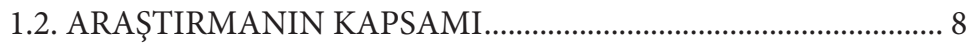

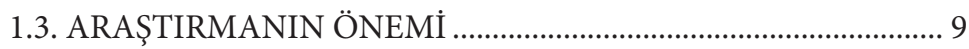

1.4. ARAŞTIRMANIN SINIRLILIKLARI ………………………….... 10

\section{BÖLÜM}

KAVRAMSAL ÇERÇEVEDE MEDYA

DEĞERLENDİRMESİ ...................................................... 11

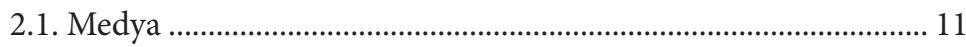

2.1.1. Medyanın Tarihsel Gelişimi.................................................... 12

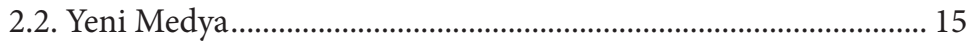

2.2.1. Yeni Medyanın Tarihsel Gelişimi............................................ 17



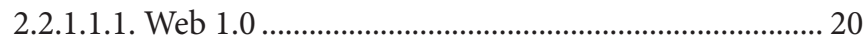

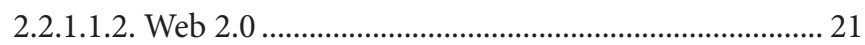

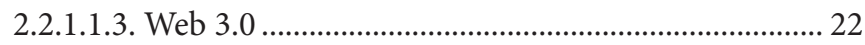

2.2.2. Dijital Dönüşüm Ekseninde Sosyal Medya .......................... 23

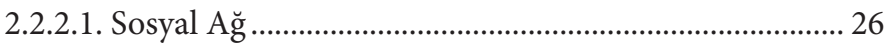

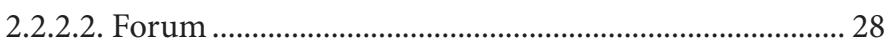



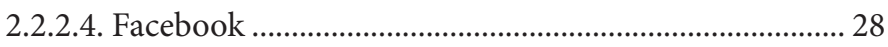

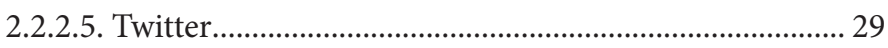

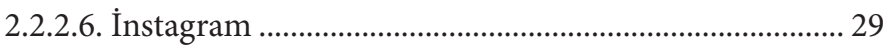




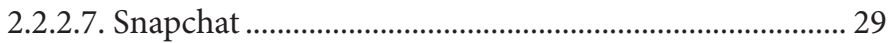

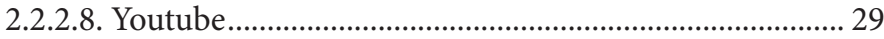

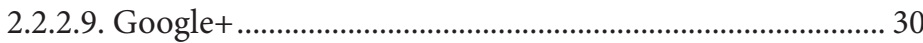

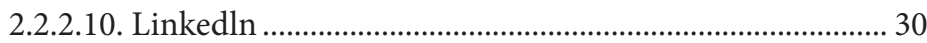

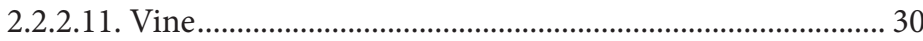

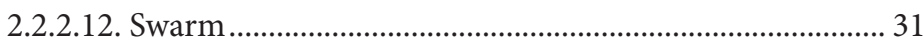

2.2.3. Sosyal Medya Ekseninde Akıllı Telefon Teknolojisi................. 31

\section{BÖLÜM}

BAĞIMLILIK MI KULLANIM BOZUKLUĞU MU? ............... 35



3.1.1. Teknoloji Kullanım Bozukluğu …………………………..... 39

3.1.2. Sosyal Medya Kullanım Bozukluğu ......................................... 42

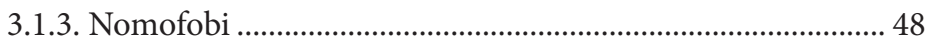

\section{BÖLÜM}

YÖNTEM ve METOD...........................................................51

4.1. Araştırma Metodolojisi ....................................................................... 51

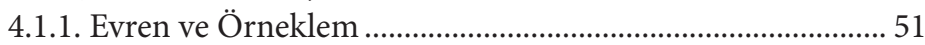

4.1.2. Veri Toplama Araçları ............................................................ 52

4.1.2.1. Katılımc1 Demografik Veri Formu................................. 52

4.1.2.2. Sosyal Medya Kullanım Bozukluğu

Ölçeği-Uzun Formu (SMKBÖ-UF) ............................................. 53

4.1.2.3. Young İnternet Bağımlılı̆̆ı Testi Kısa

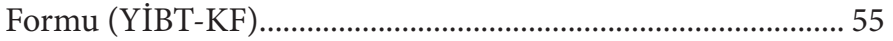

4.1.2.4. Akıllı Telefon Bağımlılı̆̆ı Ölçeği Kısa Formu

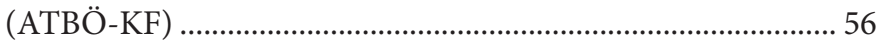

4.1.2.5. Nomofobi Ölçeği ............................................................. 56

4.1.2.6. Bergen Facebook Kullanım Bozukluğu

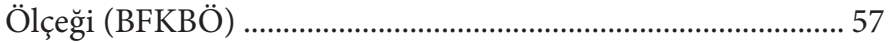

4.1.3. Araştırmada Kullanılan İşlem ................................................... 58

\section{BÖLÜM}

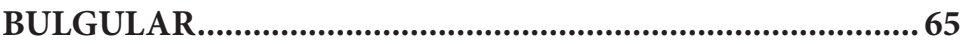






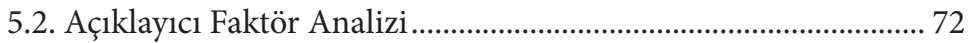



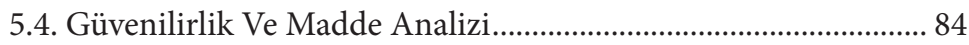



5.6. Ölçüt Dayanaklı Geçerlilik .............................................................. 95

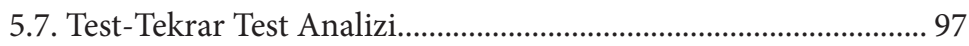

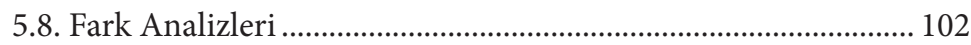

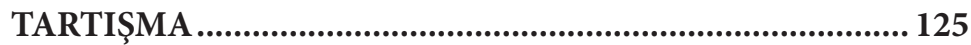

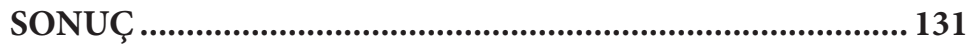

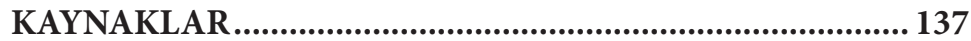




\section{KISALTMALAR}

Afa: $\quad$ Açılkayıcı Faktör Analizi

Atbö-Kf: Akıllı Telefon Bağımlılı̆̆ı Ölçeği Kısa Formu

Bfkbö : $\quad$ Bergen Facebook Kullanım Bozukluğu Ölçeği

C.r.: $\quad$ Construc Reliability

Darpa: Amerika Birleşik Devletleri Savunma Bakanlığı İleri Araştırma Projeleri Ajansı

Dfa: Doğrulayıcı Faktör Analizi

Edvac: Elektronic Discrete Variable Automatıc Computer

Enıac: Elektronic Numerical Integrator And Computer

Html: $\quad$ Hyper Text Markup Language

Ibm: International Business Machines

Kmo: $\quad$ Kaiser-Mayer-Olkin

Ram: Random Access Memory

Smkbö : $\quad$ Sosyal Medya Kullanım Bozukluğu Ölçeği

Smkbö-Uf: Sosyal Medya Kullanım Bozukluğu Ölçeği-Uzun Formu

Www: $\quad$ World Wide Web

Yibt-Kf: $\quad$ Young İnternet Bağımlılı̆̆1 Testi Kısa Formu 


\section{KAYNAKLAR}

\section{Kitaplar}

AMERICAN PSYCHİATRIC ASSOCIATION, Diagnostic And Statistical Manual Of Mental Disorders (DSM-IV-TR) (4th ed. Text Rev.), DC: Author, Washington, 2000.

AMERICAN PSYCHIATRIC ASSOCIATION, Diagnostic and Stattstical Manual Of Mental Disorders DSM-5, American Psychiatric Publishing, 2013.

ARKONAÇ Oğuz, Psikotik Bozukluklar ve Tedavileri, Nobel, İstanbul, 1996.

ARTHUR Brian, Teknolojinin Doğası, Çev. İdil Çetin, Optimist Yayıncilık, İstanbul, 2011.

AYAN Buğra, Sosyal Ağlar Tarihi, Abaküs Yayınları İstanbul, 2016.

AZIZZ Aysel, Radyo Televizyonla Eğitim, Ankara Üniversitesi, Eğitim Araştırmaları Merkezi Yayını, Ankara, 1982.

AZİZ Aysel, Radyo ve Televizyona Giriş, Ankara Üniversitesi Siyasal Bilgiler Yayınları, Ankara, 1981.

AZİZ Aysel, Televizyon ve Radyo Yayıncılığı, Hiperlink Yayınları, İstanbul, 2013.

BERGER Peter Ludwig, 2012; aktaran Deniz Yengin, Yeni Medya ve Dokunmatik Toplum, Derin Yayınları, İstanbul, 2014.

BLACK Donald W. \& GRANT Jon E., DSM-5 Guidebook: The Essential Companion To The Diagnostic and Statistical Manual of Mental Disorders, American Psychiatric Publishing, 2014. 
BLACKMAN Lisa, Immaterial Bodies. Affect, Embodiment, Mediation, Sage, London, 2012.

BRIGGS Asa ve BURKE Peter, Medyanın Toplumsal Tarihi, Çev. Ümit Hüsrev Yolsal ve Erkan Uzun, Kırmızı Yayınları, İstanbul, 2011.

BROWNE M. W. \& CUDECK R., "Alternative Ways Of Assessing Model Fit”, K. A. Bollen and J. S. Long (Eds.), Testing structural equation models, Newbury Park, 1993.

BÜYÜKÖZTÜRK Şener, Veri Analizi El Kitabı, Pegem Yayınları, Ankara, 2005.

CASTELLS Manuel, Networks Of Outrage And Hope: Social Movements In The Internet Age, Cambridge, Polity, 2012.

CASTELLS Manuel, Enformasyon Çağı: Ekonomi, Toplum ve Kültür-Ăg Toplumunun Yükselişi, Çev. Ebru Kılıç, İstanbul Bilgi Üniversitesi Yayınları, İstanbul, 2008.

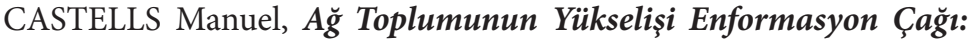
Ekonomi, Toplum ve Kültür, Çev. Ebru Kılıç, Bilgi Üniversitesi Yayınları, İstanbul, 2005.

CHANDLER Danıel ve MUNDAY Rob, Medya ve İletişim Sözlüğ̈̈̈, Çev. Babacan Taşdemir, İletişim Yayınları, İstanbul, 2018.

ÇAMDERELİ Mete, İletişime Giriş, Dem Yayınları, İstanbul, 2015.

DAY Robert A., Bilimsel Makale Nasıl Yazılır?, Çev. Gülay Aşkar Altay, Tübitak Yayınları, 2000.

DEVELLİS Robert F., Ölçek Geliştirme Kuram Ve Uygulamalar, Nobel Yayıncılık, 2017.

DİCLEMENTE Carlo C., Addiction and Change, Çev. Ezgi Ildırım ve Hanife Ugur Kural, Nobel, Ankara, 2016.

DUMAN Kenan, "Sosyal Ağ Üzerine Teorisel Çalışmalar ve Sosyal Davranış Teorilerinin İncelenmesi”, Ali Büyükaslan ve Ali Murat Kırık, (ed.), Sosyal Medya Araştırmaları III, Çizgi Kitabevi Yayınları, Konya, 2016.

EYMEN U. Erman, SPSS 15.0 İle Veri Analizi, İstatistik Merkezi, 2007. GREENFIELD David, Virtual Addiction: Help For Netheads, Cyberfreaks, And Those Who Love Them, New Harbinger Publications, Oakland, 1998.

GÜNGÖR Nazife, İletişim, Kuramlar ve Yaklaşımlar, Siyasal Kitabevi, Ankara, 2011.

GUNELIUS S., 30-Minute Social Media Marketing, McGraw-Hill, United States of American, 2011. 
ERASLAN Levent, Sosyal Medyayı Anlamak, Nobel Yaşam, Ankara, 2016.

HALL Frania, Dijital Yayıncılık, Profil Yayıncılık, İstanbul, 2014, s. 54.

HOOD Bruce, Benlik Yanılsaması, Çev. Eyüphan Özdemir, Ayrıntı Yayınları, İstanbul, 2014.

KARA Tolga, Sosyal Medya Endüstrisi, Beta Yayıncllı, İstanbul, 2013.

KARADOĞAN DORUK Ece vd, "Sosyal Medya Kullanıcılarının Sanal ve Gerçek Hayattaki Protestolara Katılma Durumlarının Karşılaştırılması ve Sanal Protestoların Kullanıcı Algısı Bakımından Etkililiği", Müge Demir, (ed.), Yeni Medya Üzerine Vol.2, Literatürk Academia, 2014.

KARAGÖZ Yalçın, Spss ve Amos Uygulamaları İstatistksel Analizler, Nobel Yayınevi, Ankara, 2016.

KALAYCI Ş., SPSS Uygulamalı Çok Değişkenli İstatistik Teknikleri, Asil Yayın Dağıtım, Ankara, 2005.

KLINNE Rex B., Principles And Practise OfStructural Equation Modeling, The Guilford Press, New York, 2011.

KLINNE Rex B., "Exploratory and confirmatory factor analysis", Y. Petscher ve C. Schatsschneider, (ed.), Applied Quantitative Analysis in the Social Sciences, New York, 2013.

KRING Ann M., JOHNSON Sheri L., DAVİSON Gerald C., NEALE John M., Abnormal Psychology, Çev. Muzaffer Şahin, Nobel, Ankara, 2017.

KÖROĞLU Ertuğrul, Psikiyatri El Kitabı, Hyb Yayıncılık, Ankara, 2013.

KRANZLER Henry and Lİ T.K., What is addiction? Alcohol Research and Health, 2008.

LAUGHEY Dan, Medya Çalışmaları, Çev. Ali Toprak, Kalkedon Yayınları, İstanbul, 2010.

LAUGHEY Dan, Key Times in Media Theory, Open University Press, New York, 2007.

NAİK U. ve SHİVALINGAİAH D., Corparative Study Of Web 1.0, Web 2.0 and Web 3.0, Allahabad, 2008; aktaran Selva Ersöz Karakulakoğlu, "Geleceğin Web Teknolojileri: Web 3.0 ve Etkileşim", Özlem Oğuzhan (ed.), İletişimde Sosyal Medya Sosyal Medyada Etkileşim, Kalkedon Yayınları, İstanbul, 2015.

ÖZDAMAR Kazım, Ölçek Ve Test Geliştirme, Nisan Yayın Evi, Eskişehir, 2016. 
ÖZTÜRK Orhan ve ULUŞAHİN Aylin, Ruh Săgliğı ve Bozuklukları, Bayt Yayınevi, Ankara, 2016.

ÖZGÜR Aydın Ziya ve ŞİŞMAN Aytekin (Ed.), İletişim Çalışmaları 2015, Sakarya Üniversitesi Yayınları, Sakarya, 2015.

TABACHNİCK Barbara G. ve FIDELL Linda S., Using Multivariate Statistics, Pearson, Boston, 2013.

TOKGÖZ Oya, Temel Gazetecilik, İmge Kitabevi Yayınları, Ankara, 1994.

TOKGÖZ Oya, Temel Gazetecilik, İmge Kitabevi Yayınları, Ankara, 2017.

TÜRKOĞLU Tanol, Dijital Kültür, Beyaz Yayınları, İstanbul, 2010.

WEINBERG T., The New Community Rules: Marketing On The Social Web, O’Reilly Media, Inc., 2009, s. 1.

VARNALI Kaan, Dijital Tutulma, MediaCat, İstanbul, 2013.

YENGIN Deniz, Yeni Medya ve Dokunmatik Toplum, Derin Yayınlar1, İstanbul, 2014.

YOUNG Kimberly, The Evolution Of Internet Addiction Disorder, Christian Montag \& Martın Reuter (Eds.), Internet Addiction: Neuroscientific Approaches And Therapeutical Interventions, New York, 2015.

YÜKSEL Okan, "Bilişim Teknolojileri ve Yeni Medya, Yeni Dünya”, Berrin Kalsın (ed.), Tüm Boyutlarıla Internet Haberciliği, Gece Kitaplığı, Ankara, 2017.

\section{Makaleler}

AKIN Murat, "A Research on the Impacts of the Young People's Internet Addiction Levels and Their Social Media Preferences", International Review of Management and Marketing, 2014.

AKTAŞ Hasret ve YILMAZ Nurcan, "Smartphone Addiction İn Terms Of The Elements Of Loneliness And Shyness Of University Youth", International Journal of Social Sciences and Education Research, 2017.

ALBRECHT U. vd, "Diagnostic İnstruments For Behavioural Addiction: An Overwiev”, GMS Psycho-Social-Medicine, 2007.

ANDREASSEN Cecilia Schou, "Online Social Network Site Addiction: A Comprehensive Review”, Current Addiction Reports, 2015.

ANDREASSEN C., GRIFFITHS Mark D., GJERTSEN Sırı Renate, Elfrıd KROSSBAKKEN, KVAM Sırı, PALLESEN Ståle “The relationships between behavioral addictions and the five-factor model of personality", Journal of Behavioral Addictions, 2013. 
ANDREASSEN Cecilie Schou ve PALLESEN Stale, "Social Network Site Addiction - An Overview", Current Pharmaceutical Design, 2014.

ANDREASSEN Cecilie Schou, "Development Of A Facebook Addiction Scale", Psychological Reports, 2012.

AYAS T. ve HORZUM M.B., "İlköğretim Öğrencilerinin Sanal Zorba Ve Mağdur Olma Durumu”, Illköğretim Online, 2012.

AYDIN Berna Z., "Faktör Analizi Yardımıyla Performans Ölçütlerinin Boyutlarının Ortaya Konulması", 8. Türkiye Ekonometri Ve İstatistik Kongresi, İnönü Üniversitesi, 2007.

BECAN C., "Sosyal Medya Bağımlılığının Haber Takibi Motivasyonları Üzerine Etkisi”, Erciyes Üniversitesi İletişim Fakültesi Akademik Dergisi, 2018.

CHENG Cecilia ve Lİ Angel Yee-Iam, "Internet Addiction Prevalence And Quality Of (Real) Life: A Meta-Analysis Of 31 Nations Across Seven World Regions", Cyberpsychology, Behavior and Social Networking, 2014.

AKIN Ahmet, ÖZBAY Ahmet, BAYKUT İhsan, "Sosyal Medya Kullanımı Ölçeği’nin Türkçe Formu'nun Geçerliği ve Güvenirliği”, Uluslararası Sosyal Araştırmalar Dergisi, 2015.

CORREIA Ana-Paula, "Exploring The Dimensions Of Nomophobia: Development And Validation Of A Self-Reported Questionnaire", Computers in Human Behavior, 2015.

ÇAKMUR Hülya, "Araştırmalarda Ölçme, Güvenilirlik ve Geçerlik", TAF Preventive Medicine Bulletin, 2012.

DURKEE T., KAESS M., CARLI V., PARZER P., WASSERMAN C., FLODERUS B.,WASSERMAN D., "Prevalence of pathological internet use among adolescents in Europe: Demographic and social factors", Addiction, 2012.

DURMUŞ Beril, YURTKORU Serra, Yeşim Ulusu \& Bülent Kılıç, Facebook'tayız Sosyal Paylaşım Ağlarının Bireylere ve İşletmelere Yönelik Incelenmesi, Beta Yayıncılık, İstanbul, 2010.

ERCAN İlker ve KAN İsmet, "Ölçeklerde Güvenilirlik ve Geçerlik", Uludağ Üniversitesi Tıp Fakültesi Dergisi, 2004.

FRED Davis, "Perceived Usefulness, Perceived Ease of Use, and User Acceptance of Information Teknology", Management Information Systems Quartely, 1989.

GÖKER Göksel, "İletişimin Mcdonaldlaşması: Sosyal Medya Üzerine Bir İnceleme”, International Periodical For The Languages, Literature and History of Turkish or Turkic, 2015. 
GRIFFITHS Mark, “Technological Addictions”, Clinical Psychology Forum, Division Of Clinical Psychology Of The British Psychol Soc, 1995.

GRIFFITHS Mark D., "Internet addiction: An issue for psychopathology?", Clinical Psychology Forum, 1996.

GRIFFITHS Mark, "Does Internet and Computer "Addiction" Exist Some Case Study Evidence”, Cyberpsychology \& Behavior, 2000.

GRIFFITHS Mark, "Internet Gambling: Issues, Concerns And Recommendations", CyberPsychology \& Behavior, 2003.

GRIFFITHS Mark, "Internet Sex Addiction: A Review Of Empirical Research", Addiction Research \& Theory, 2012.

GÜNGÖR Duygu, "Psikolojide Ölçme Araçlarının Geliştirilmesi ve Uyarlanması Kılavuzu”, Türk Psikoloji Yazıları, 2016.

HAZAR Çetin Murat, "Sosyal Medya Bağımlılı̆̆ı: Bir Alan Çalışması”, Gazi Üniversitesi İletişim Fakültesi Dergisi, 2011.

JENARO C., FLORES N., GÓMEZ-VELA M., GONZÁLEZ-GİL F., \& CABALLO C., "Problematic İnternet And Cell-Phone Use: Psychological, Behavioral, And Health 103 Correlates", Addiction Research \& Theory, 2007.

KALKAN M., "Predictiveness of interpersonal cognitive distortions on university students problematic internet use", Children and Youth Services Review, 2012.

KIM Jang Hyun, KİM Min-Sun \& NAM Yoonjae. "An Analysis Of Self-Construals, Motivations, Facebook Use And User Satisfaction", International Journal of Human-Computer Interaction, 2010.

KING Anna Lucıa Spear, Valença A. M. \& NARDİ Antonio Egidio, "Nomophobia: The Mobile Phone İn Panic Disorder With Agoraphobia: Reducing Phobias Or Worsening Of Dependence”, Cognitive and Behavioral Neurology, 2010.

KING Anna Lucia Spear, VALENÇA A. M., SİLVA A. C. O., BACZYNSKİ T., CARVALHO M. R. \& NARDİ Antonio Egidio, "Nomophobia: Dependency On Virtual Environments Or Social Phobia”, Computers in Human Behavior, 2013.

KORUCU Agah Tuğrul ve USTA Ertuğrul, "Sosyal Medya Öğretmen-Öğrenci Etkileşimi Ölçeğinin Geliştirilmesi”, Elementary Education Online, 2017.

KRANZLER Henry and Lİ T.K., "What İs Addiction?", Alcohol Research and Health, 2008. 
KUSS Daria J. ve GRIFFITHHS Mark D., "Online Gaming Addiction İn Children And Adolescents: A Review Of Empirical Research", Journal of Behavioral Addictions, 2012.

KUSS, D. J., LOUWS, J., \& WIERS, R. W. “Online Gaming Addiction? Motives Predict Addictive Play Behavior İn Massively Multiplayer Online Role-Playing Games", Cyberpsychology, Behavior and Social Networking, 2012.

KWON Ohbyung ve WEN Yixing, "An Empirical Study Of The Factors Affecting Social Network Service Use", Computers in Human Behavior, 2010.

MARSH H. W., HAU K. T., ARTELT C., BAUMERT J. \& PESCHAR J. L., "OECD’s Brief Self-Report Measure of Educational Psychology's Most Useful Affective Constructs: Cross-cultural, Psychometric Comparisons Across 25 Countries", International Journal of Testing, 2006.

MAZZONİ Elvis ve IANNONE Maria, "From High School To University: Impact Of Social Networking Sites On Social Capital İn The Transitions Of Emerging Adults", British Journal of Educational Technology.

MESSİAS E., CASTRO J., SAİNİ A., UMSAN M., \& PEEPLES D., "Sadness, suicide, and their association with video game and internet overuse among teens: Results from the Youth Risk Behavior Survey 2007 and 2009", Suicide and Life-Threatening Behavior, 2011.

MCCUTCHEON A. L., Latent class analiysis, 1987; aktaran Duygu Güngör, Psikolojide Ölçme Araçlarının Geliştirilmesi ve Uyarlanması Kılavuzu, Türk Psikoloji Yazıları, 2016.

NOYAN Cemal Onur, ENEZ DARÇIN Aslı, NURMEDOV Serdar, YILMAZ Onat, DİLBAZ Nesrin, "Akıllı Telefon Bağımlılığı Ölçeğinin Kısa Formunun Üniversite Öğrencilerinde Türkçe Geçerlilik Ve Güvenilirlik Çalışması", Anadolu Psikiyatri Dergisi, 2015, 7381.

TUREL Ofir, SERENKO A., \& GILLES P., "Integrating Technology Addiction And Use: An Empirical İnvestigation Of Online Auction Users", MIS Quarterly, 2011.

OLENIK-SHEMESH D., HEIMAN Tali, EDEN Sigal, "Cyberbullying Victimization İn Adolescence: Relationships With Loneliness And Depressive Mood", Emotional \& Behavioral Difficulties, 2012. 
OTRAR Mustafa ve ARGIN Süleyman, “Öğrencilerin Sosyal Medyaya İlişkin Tutumlarını Belirlemeye Yönelik Bir Ölçek Geliştirme Çalışması”, Eğitim ve Öğretim Araştırmaları Dergisi, 2015.

ÖZEL E. K., "Çalışanların Twitter Kullanımının, Kurum İmajına Etkisi: Türkiyede Bir Anket Çalışması”, Journal of Yasar University, 2014.

ÖZGÜR H., "Sosyal Ağların Benimsenmesi ve Eğitsel Bağlamda Kullanımı Arasındaki İlişkinin Çeşitli Değişkenler Açısından İncelenmesi”, Dicle Üniversitesi Sosyal Bilimler Enstitüsü Dergisi, 2013.

PATWARDHAN Padmini ve YANG Jin, "Internet Dependency Relations and Online Consumer Behavior", Journal of Interactive Advertising, 2017.

PERREN S., DOLEY Julıan, SHAW Thérèse, CROSS Dorıan, "Bullying In School And Cyberspace: Associations With Depressive Symptoms İn Swiss And Australian Adolescents", Child and Adolescent Psychiatry and Mental Health, 2010.

QUITTTNER J., "Divorce Internet Style: A report for the American Academy of Matrimonial Lawyers", Time, 1997.

RAACKE J., BONDS-RAACKE J., "MySpace and Facebook: Applying the Uses and Gratifications Theory to Exploring Friend-Networking Sites", CyberPsychology \& Behavior, 2008.

REİD Donna \& REİD Frasher J. M., “Text Or Talk? Social Anxiety, Loneliness, And Divergent Preferences For Cell Phone Use", CyberPsychology and Behavior, 2007.

RYAN Tracı, CHESTER Andrea, REECE John ve XENOS Sophia, "The Uses And Abuses Of Facebook: A Review Of Facebook Addiction”, Journal of Behavioral Addictions, 2014.

SALEHAN Mohammad \& NEGAHBAN Arash, "Social networking on smartphones: When mobile phones become addictive", Computers in Human Behavior, 2013.

SALİCETİ Francesca, "Internet Addiction Disorder (IAD)", Procedia - Social and Behavioral Sciences, 2015.

SARIÇAM Hakan ve ADAM KARDUZ Fatma Firdevs, "Sosyal Medya Kullanım Bozukluğu Ölçeğinin Türk Kültürüne Uyarlanması: Geçerlik ve Güvenirlik Çalışması”, Eğitimde ve Psikolojide Ölçme ve Değerlendirme Dergisi, 2018.

SCHERMELLEH-ENGEL Karin, MOOSBRUGGER Helfried, HANS Müller, "Evaluating the Fit of Structural Equation Models: Tests of Significance and Descriptive Goodness of Fit Measures", Methods of Psychological Research, 2003. 
SEZGİN S., EROL O., DULKADİR N. ve KARAKAŞ A., "Bilgisayar ve Öğretim Teknolojileri (BÖTE) Öğrencilerinin Facebook Kullanım Amaçları ve Eğitsel Bağlamda Kullanımı İle İlgili Görüşleri: MAKÜ Örneği”, In International Educational Technology Conference, İstanbul, 2011.

STEVENS Laura, VERDEJO-GARCIA Antonio, GOUDRIAAN Anna, ROEYERS Herbert, DOM Geert, VANDERPLASSCHEN Wouter, "Impulsivity As A Vulnerability Factor For Poor Addiction Treatment Outcomes: A Review Of Neurocognitive Findings Among Individuals With Substance Use Disorders", The Journal of Substance Abuse Treatment, 2014.

SULTAN Abdullah J., "Addiction To Mobile Text Messaging Applications İs Nothing To "Lol” About", The Social Science Journal, 2014.

ŞAHIN Cengiz ve YAĞCI Mustafa, "Sosyal Medya Bağımlılığı Ölçeği-Yetişkin Formu: Geçerlilik ve Güvenirlik Çalışması”, Ahi Evran Üniversitesi Kırşehir Ĕ̈itim Fakültesi Dergisi, 2017.

TOSSEL Chad, KORTUM Phil, SHEPARD Clayton, RAHMATİ Ahmad, "Exploring Smartphone Addiction: İnsights From LongTerm Telemetric Behavioral Measures”, IJIM, 2015.

TUREL Ofir, SERENKO Alexander, GİLES Paul, "Integrating Technology Addiction And Use: An Empirical İnvestigation Of Online Auction Users", MIS Quarterly, 2011.

VAN DEN EİJNDEN, R. J. J. M., LEMMENS, J. S., \& VALKENBURG, P. M., "The Social Media Disorder Scale", Computers in Human Behavior, 2016.

WANG J. L., JACKSON L. A., GASKIN J. ve WANG H. Z., "The Effects Of Social Networking Site (SNS) Use On College Students' Friendship And Well-Being", Computers in Human Behavior, 2014.

YBARRA M. L. \& MİTCHELL K. J., "Online Aggressor/Targets, Aggressors, And Targets: A Comparison Of Associated Youth Characteristics", Journal of Child Psychology \& Psychiatry, 2004.

YANG Shu Ching ve TUNG Chieh-Ju, "Comparison Of Internet Addicts And Non-Addicts In Taiwanese High Schools", Computers in Human Behavior, 2007.

YILDIRIM Çağlar, YILDIRIM Soner, SUMUER Evren, ADNAN Müge, "A Growing Fear: Prevalence Of Nomophobia Among Turkish College Students”, Information Development, 2015.

YILMAZSOY B. ve KAHRAMAN M., "Üniversite Öğrencilerinin Sosyal Medya Bağımlılığı İle Sosyal Medyayı Eğitsel Amaçlı Kulla- 
nımları Arasındaki İlişkinin İncelenmesi: Facebook Örneği”, Journal of Instructional Technologies \& Teacher Education, 2017.

YOUNG Kimberly S., "Internet addiction: The emergence of a new clinical disorder", CyberPsychology \& Behavior, 1998.

YOUNG Kimberly, "Internet Addiction: A New Clinical Phenomenon and Its Consequences." American Behavioral Scientist, 2004.

YÜKSEKBİLGİLİ Zeki, "Sosyal Medya Pazarlama Aktiviteleri Ölçeğinin Türkçeye Uyarlanması: Güvenilirlik ve Geçerlilik Çalışması”, Selçuk Üniversitesi, Sosyal Bilimler Meslek Yüksekokulu Dergisi, 2018.

ZUNIGA, H. G., JUNG, N. ve VALENZUELA, S., "Social Media Use for News and Individuals' Social Capital, Civic Engagement and Political Participation", Journal of Computer Mediated Communication, 2012.

\section{Dergiler}

“Sosyal Medyanın Yeni Müfettişleri”, MediaCat, 281, Haziran 2018.

PİTTA D. A. ve FOWLER D., Internet Comunty Forums: An Untapped Resource For Customer Marketers, Journal of Customers Marketing, 22 (5), 2005.

QUITTNER J., "Divorce Internet Style: A report for the American Academy of Matrimonial Lawyers", Time, 1997.

\section{Tezler}

COOPER Stephanıe, Effects Of Problematıc Technology Use, Rutgers, The State University Of New Jersey, The Graduate School Of Applıed And Professıonal Psychology, New Jersey, 2016(Yayımlanmış Doktora Tezi).

EGGER O. ve RAUTERBERG M., Internet Behaviour and Addiction, 1996; aktaran Çiğdem Tekin, Cep Telefonu Problemli Kullanım (PU) Ölçeğinin Türkçe’ye Uyarlanması: Geçerlik ve Güvenirlik Çalışması, İnönü Üniversitesi, Sağlık Bilimleri Enstitüsü, Malatya, 2012(Yayımlanmış Yüksek Lisans Tezi).

İÇİRGIN Ömer, Üniversite Öğrencilerinin Sosyal Medya Kullanım Alışkanlıkları Ve Motivasyonları, Selçuk Üniversitesi, Sosyal Bilimler Enstitüsü, Halkla İlişkiler Ve Tanıtım Anabilim Dalı, Konya, 2018(Yayımlanmış Yüksek Lisans Tezi).

KARTAL Hasan Basri, Envanter Sinıflandırmada Yapay Öğrenme Yöntemlerinin Kullanımı ve Destek Vektör Makineleri ile Bir 
Uygulama, İstanbul Teknik Üniversitesi Fen Bilimleri Enstitüsü, İşletme Mühendisliği Anabilim Dalı, İşletme Mühendisliği Programı, İstanbul, 2012(Yayımlanmış Yüksek Lisans Tezi).

KATHLEEN REED Lor1, A Technological Dis-Ease: Scientıfic Discourses, Mass Media, And The 'Truths' About 'Computer Addiction', Graduate College of the University of Illinois, Urbana, 2000(Doctor of Philosophy in Communications).

Przybylski ve Weinstein, 2013; aktaran David Franklin Meland, Surviving The Digital Age, Gonzaga University, Faculty in Communication and Leadership Studies, United States, 2014(Master's Project).

SHAJIDAN Aihemaiti, Twitter'ın Halkla İlişkiler Amaçlı Kullanımı: Türkiye'deki Markalar Üzerine Bir Araştırma, Sosyal Bilimler Enstitüsü, İstanbul Ticaret Üniversitesi, İstanbul, 2017(Yayımlanmış Yüksek Lisans Tezi).

SERARSLAN Meral, Radyo Televizyon Düzeninde Değişimler Arayışlar ve Türkiye, Sosyal Bilimler Enstitüsü, Marmara Üniversitesi, İstanbul, 1993(Yayımlanmış Yüksek Lisans Tezi).

TEKAYAK Halil Volkan, Ak-Tek Sağlıkta Sosyal Medya Kullanımı Ölçeğinin Geliştirilmesi Ve Aile Hekimlerinin Sosyal Medya Kullanımlarının Kişisel Ve Mesleki Gelişimlerine Etkilerinin Değerlendirilmesi, Çukurova Üniversitesi, Tip Fakültesi, Aile Hekimliği Anabilim Dalı, Adana, 2017(Yayımlanmış Uzmanlık Tezi).

ÜNAL Aylin Tutgun, Sosyal Medya Bağımlılığı: Üniversite Öğrencileri Üzerine Bir Araştırma, Marmara Üniversitesi, Sosyal Bilimler Enstitüsü Gazetecilik Ana Bilim Dalı, İstanbul, 2015(Yayımlanmış Doktora Tezi).

\section{İnternet Kaynakları}

AKBULUT Ural, ODTÜ Kimya Bölümü, http://www.uralakbulut.com. tr/wp-content/uploads/2009/11/CEP-TELEFONU-HAYATIMIZA-NASIL-G\%C4\%B0RD\%C4\%B0.EYL\%C3\%9CL-2011-Sondoc.pdf (Erişim Tarihi: 21.03.2019)

AKIN Ahmet, ÖZBAY Ahmet, BAYKUT İhsan, Sosyal Medya Kullanımı Ölçeği’nin Türkçe Formu'nun Geçerlik Ve Güvenirliği, 2015, https://toad.halileksi.net/sites/default/files/pdf/sosyal-medya-kullanimi-olcegi-toad.pdf (Erişim Tarihi: 20.12.2018)

BAKIR AYGAR Bilge ve UZUN Bilge, Sosyal Medya Bağımlılı̆̆ı Ölçeğinnin Geliştirilmesi: Geçerlik ve Güvenirlik Çalışmaları, 2017, 
https://toad.halileksi.net/sites/default/files/pdf/sosyal-medya-bagimliligi-olcegi-toad_0.pdf(Erişim Tarihi: 20.12.2018)

Digital In 2018 In Western Asia, http://www.mediacatonline.com/wp-content/uploads/2018/05/we-are-social-digital-in-2018.pdf (Erişim tarihi: 30.01.2019)

Digital In 2018, https://www.slideshare.net/wearesocial/2018-digital-yearbook-86862930 (Erişim Tarihi: 04.03.2019)

DAVIS Linda Lindsey, Instrument review: Getting the most from a panel of experts, 1992, https://www.academia.edu/33941389/Instrument_review_Getting_ the_most_from_a_panel_of_experts (Erişim Tarihi: 05. 01. 2019)

DAVIS Richard A., A Cognitive Behavioral Model OfPathological İnternet Use, 2000, https://www.researchgate.net/publication/223337034_A_cognitive_behavioral_model_of_pathological_Internet_use_PIU (Erişim Tarihi: 09. 04. 2019)

DINICOLA M. D., Pathological İnternet Use Among College Students: The Prevalence Of Pathological Internet Use And Its Correlates, Unpublished Doctoral Dissertation, Ohio University, 2004; aktaran Esra Ceyhan vd., Problemli İnternet Kullanımı Ölçeğinin Geçerlik ve Güvenirlik Çalş̧maları, https://toad. edam.com.tr/sites/default/files/pdf/problemli-internet-kullanimi-olcegi-toad. pdf (Erişim tarihi: 31.01. 2019)

ERDEM Haluk, TÜREN Ufuk, KALKIN Gökdeniz, Mobil Telefon Yoksunluğu Korkusu (Nomofobi) Yayıllmı: Türkiye’den Üniversite Öğrencileri ve Kamu Çalışanları Örneklemi, 2017, http://dergipark.gov.tr/download/article-file/273134 (Erişim Tarihi: 03. 01. 2019).

FIRAT Nuray ve BARUT Yaşar, Sosyal Medya Bağımlllğ̆ Ölçeği (SMBÖ)'nin Geliştirilmesi: Geçerlik Ve Güvenirlik Çalş̧mast, 2018, https://toad.halileksi.net/ sites/default/files/pdf/sosyal-medya-bagimliligi-olcegi-toad_2.pdf, (Erişim Tarihi: 23. 01. 2019).

KWON Min, KIM Dai-Jin, CHO Hyun, YANG Soo, The Smartphone Addiction Scale: Development And Validation Of A Short Version For Adolescents, 2013, https:// www.researchgate.net/publication/259589326_The_Smartphone_Addiction_ Scale_Development_and_Validation_of_a_Short_Version_for_Adolescents (Erişim Tarihi: 03.01.2019)

KUTLU Mustafa, SAVCI Mustafa, DEMIR Yasin, AYSAN Ferda, Young İnternet Bağımlllğ̆ Testi Kısa Formunun Türkçe uyarlaması: Üniversite öğrencileri ve ergenlerde geçerlilik ve güvenilirlik çalışması, 2016, https://www.ejmanager.com/mnstemps/91/apd_17_11_08. pdf?t=1555229763 (Erişim Tarihi: 02.01.2019)

LAWSHEC.H., A quantitative approach to content validity, 1975, http:// citeseerx.ist.psu.edu/viewdoc/download?doi=10.1.1.460.9380\&rep=rep1\&type $=$ pdf (Erişim Tarihi: 05.01.2019).

O'REILLY Tim, What is Web 2.0: Design patterns and business mo- 
dels for the next generation of software. Communications \& Strategies, 2007. https://mpra.ub.uni-muenchen.de/4578/1/MPRA_ paper_4578.pdf (Erişim tarihi:03.02.2019)

PAWLİKOWSKİ Mirko, ALTSTÖTTER-GLEİCH Christine, BRAND Matthias, Validation and psychometric properties of a short version of Young's Internet Addiction Test, 2013, https://www.researchgate. net/publication/257252791_Validation_and_psychometric_properties_of_a_short_version_of_Young's_Internet_Addiction Test (Erişim Tarihi: 01. 01. 2019)

SAVCI Mustafa, ERCENGİZ Mustafa, AYSAN Ferda, Sosyal Medya Bozukluğu Ölçeğiinin Ergenlerde Türkçe Uyarlaması, Arch Neuropsychiatry, 2018, https://toad.halileksi.net/olcek/sosyal-medya-bozuklugu-olcegi, (Erişim Tarihi: 21. 03. 2019).

ŞiŞMAN EREN Esra, Sosyal Medya Kullanım Amaçları Ölçeğinin Geliştirilmesi ve Bazı Kişisel Değişkenlere Göre İncelenmesi, https://toad.halileksi.net/sites/default/files/pdf/sosyal-medya-kullanim-amaclari-olcegi-toad.pdf (Erişim Tarihi: 20. 01. 2019)

TEKEŞ Burcu ve HASTA Derya, “ Özgecilik Ölçeği: Geçerlik ve Güvenirlik Çalışması”, Nesne Psikoloji Dergisi, https://toad.halileksi. net/sites/default/files/pdf/ozgecilik-olcegi-toad.pdf (Erişim Tarihi: 21.03.2019)

TEZBAŞARAN Ata, Likert Tipi Ölçek Geliştirme Kılavuzu. https://www.academia.edu/1288035/Likert_Tipi_\%C3\%961\%C3\%A7ek_Haz\%C4\%B1rlama_K\%C4\%Bllavuzu (Erişim Tarihi: 04.04.2019)

Türkiye İstatistik Kurumu, Bilgi Toplumu İstatistikleri, http://www. tuik.gov.tr/PreTablo.do?alt_id=1028 (Erişim Tarihi: 03.03.2019)

WALKER Leslie, What İs Social Networking Addiction?, https://www. lifewire.com/what-is-social-networking-addiction-2655246 (Erişim Tarihi: 04. 04. 2019)

YILDIRIM Gürkan, Bilgisayar ve Bilgisayarın Tarihçesi, Erzurum Atatürk Üniversitesi, 2011. https://atabilgisayardonanim.files. wordpress.com/2011/10/bilgisayar-ve-bilgisayarin-tarihcesi2.pdf (Erişim Tarihi: 03.03.2019) 